\title{
Pilot study on the responsiveness of nurses to the patient's request for complimentary medicine
}

\author{
Vesna Zupančič ${ }^{1 *}$, Katja Krope ${ }^{2}$
}

${ }^{1}$ Ministry of Health, Štefanova 5, 1000 Ljubljana, Slovenia, ${ }^{2}$ Faculty of Health Sciences Novo Mesto, Na Loko 2, 8000 Novo Mesto, Slovenia

\begin{abstract}
Introduction: When it comes to integrative medicine, the nurses are "caught in a trap" of their own views and developed competencies, as well as the views of the institution and the country where they work. Our aim was to explore what is the expected reaction of nurses to the patient's request for complementary treatment with tea in hospitals where integrative nursing has not yet been normatively recognized.

Methods: The quantitative research approach with a survey was used. Snowball sampling covered 506 persons from Southeast Slovenia, participating voluntarily: Nurses, nursing students, patients, and other persons. Respondents were to choose among the 11 previously prepared scenarios of possible responses of the nurse.

Results: Significant differences regarding the expected reaction of nurses both within the groups, as well as between the groups of respondents were found. The most possible critical response of nurses was to offer the tea which is daily available on the ward. A fifth of respondents believes that the patient's tea would be provided by the visiting relatives.
\end{abstract}

Conclusion: Due to the prepared scenarios, findings and given orientations for further research, the study can be further implemented in the international environment for empirical verification.

Key words: Quality of work; integrative approach in health care; holistic nursing practice; herbal tea; expected response

\section{INTRODUCTION}

The argument of this paper is the discussion regarding the responsiveness of nurses to the patient's request to prepare them a specific tea for the purpose of medical treatment in public hospitals where integrative medicine and nursing have not yet been normatively recognized. In the framework of the

\footnotetext{
*Corresponding author: Vesna Zupančič, Ministry of Health, Štefanova 5, 1000 Ljubljana, Slovenija. Tel.: 386-40-366-580.

E-mail: vesna.zupancic@guest.arnes.si
}

Submitted: 3 March 2017/Accepted: 20 September 2017

DOI: https://doi.org/10.17532/jhsci.2017.386 project, CAMbrella (1) gaps in the international human rights law and soft law (codes, charters, and guidelines for the treatment of patients) were recognized in the context of defining bases for the patients' rights to complementary and alternative health care. Liberalization increases accessibility, but it raises concerns about the safety of complementary and alternative treatment for patients, although all forms of treatment have to ensure that the needs of patients are safely and ethically met (2,3). A strong trend of integrative medicine and nursing has been finally established (4). As shown by the research in Slovenia, as well as in the rest of the world, the 
number of users of alternative and complementary medicine is increasing rapidly and varies between 40 and $70 \%(5,6)$. There is a noticeable trend of gradual institutionalization of individual forms of treatment (7).

When it comes to integrative medicine, nurses often find themselves in the so-called "sandwich position" between the doctor and the patient, between the system and the individuals, and between the expectations of the public, and their own competencies. Being in the role of an intermediary, informer, adviser or performer, the nurses are "caught in a trap" of their own views and developed competencies, as well as the views of the institution and the country where they work. Nevertheless, assertive responsiveness of nurses "to put things together to form something new" (8) can be seen in the development of integrative health care $(3,9,10)$.

Tea may be considered as a plant, an agricultural product, a drink, a meal service or a form of socializing. As a commodity and tradition, it is transferred from one culture to another, which can be described as a process of cultural adaptation transformed "from the tradition of one culture to the heritage of another" (11). Culture has a particularly important role in using medicinal plants and herbs in preparing tea for the purposes of medical treatment. In this context, attention should be drawn to the fact that globalization has sharply increased accessibility to herbal preparations from all parts of the world for any individual consumer (12) and drinking tea made from indigenous medicinal plants for the purposes of medical treatment is no longer the only option for the patient. One of the most basic problems regarding the use of medicinal plants and herbs for medical treatment is the absence of consistent terminology when classifying them in groups (e.g., food or food supplements). Consequently, several various regulations need to be considered and followed, including standards for their sale, which are loose (12). The WHO has published guidelines (13) for growing, collecting and manufacturing of herbs that should be considered by all countries as a template for global standardization of herbs. The EC Directive 2004/24/EC (14) is an attempt by the European Commission to further regulate the market for traditional herbal medicines, based on the higher standard of scientific evidence. A great need of concerted efforts has occurred to implement the necessary clinical trials to study the efficacy and safety of the herbal medicinal products, both individually used, or in combination with conventional medicine (12).

Ethical starting point regarding the responsiveness of nursing care providers to the request of the patient: "Nurse, my tea, please!" thus raises a discussion and focus on the three key ethical framework dimensions, in which the issues of social value, scientific validity and a favorable relationship between the risks and benefits of alternative and complementary therapy for the patient are arising (15). Two elements of the ethical code in nursing are crucial: (a) Nurses ensure that the individual receives accurate, sufficient and timely information in a culturally appropriate manner on which to base consent for care and related treatment and (b) they demonstrate professional values such as respectfulness, responsiveness, compassion, trustworthiness, and integrity (16). The American Holistic Nurses Association prepared the code for implementing holistic nursing, which states that when treating a patient, the nurse is allowed to express questions related to complementary/alternative treatment and the provider of the treatment (17). Namely, it has been found that patients who use herbs in this form do not report them as herbal medicine use unless specifically asked (12). Research findings indicate that the complementary/alternative therapy is mostly used by patients who have been disappointed by the health-care systems and traditional treatment in their country (18). It can be seen that the use of medicinal plants for the purposes of medical treatment is increasing with age, particularly in treating cold (19). The uncontrolled use of herbal teas or herbal supplements constitutes a serious risk in the elderly population due to the potential interactions with prescription medicines to control the diseases such as high blood pressure, diabetes, and other diseases associated with old age (20). Studies suggest that interactions between prescription medicines and preparations from medicinal plants occur in $30-40 \%$ of the elderly, who combine both treatments. Besides, it has been proven that the patients experience clinically significant changes in medicine efficiency if the level of self-treatment was decreased, or if the medicine dosage was increased (21). 
Therefore, the following needs to be considered: If the normative framework is not regulated, how will the nurse react to questions regarding complementary treatment with herbal medicines to consider both the patient's right to choice and decision and the principle of benefit for the patient? Concerns and ethical dilemmas emerge: What should be done? What must be done? What response is expected from the nurse, even though we are talking about a simple wish of the patient regarding tea preparation for the purpose of medical treatment?

The purpose of the research is to point out the necessary activities for recognizing the need to care, taking appropriate action and responsibility (taking care of), satisfying the concrete needs (implementing the care), and creating a relationship (receiving the care) (22) with patients who resort to or have the intention to resort to alternative/complementary treatment. The need of considering several possible explanations as correct is respected (23) as well as identification of possible trends in the given circumstances (24). In this case, understanding individual problems is only possible by observations from different perspectives.

The aim of the study was to verify what is the expected reaction of nurses to the patient's request for complementary treatment with tea in hospitals. Furthermore, the aim was also to provide empirical evidence about the appropriateness and the feasibility of an innovative approach to examining this issue. The primary role of a pilot study is to examine the feasibility and utility of the research efforts to achieve the objectives, being an initial and innovative step in researching, intended for use in studies of a larger volume (25-27). We set the following research questions:

- What is the expected reaction of nurses to the request of the patient: "Nurse, my tea, please!?" and

- Do the anticipated scenarios adequately describe the range of possible responses of nurses to the patient's request for preparing their tea for the purpose of complementary medical treatment?

\section{METHODS}

The pilot study was performed in phases from February to June 2015 within the framework of the project developing competencies for implementing integrative treatment and care of the patient: "Nurse, my tea, please!," which was one of the projects within the scheme called "creative path to practical knowledge," supported by the Slovene human resources development and scholarship fund. The quantitative research approach with a survey was used. The questionnaire was developed on the basis of qualitative analysis of the scientific resources and minutes taken by the project group (14 people). The method of cognitive interview was used for primary feasibility check of the questionnaire (28). The purpose of the survey was to collect relevant information about the expected reaction of nurses to the patient's request and to check the feasibility of the research plan (29) including the developed instrument (30).

\section{Ethical considerations}

The ethical approval was not obtained. All respondents participated in the survey on a voluntary basis, giving an informed consent. For the purpose of interviewing the patients and nurses in the hospital, the Institutional Review Board consent has been obtained. Questions and scenarios were designed in a way that privacy of respondents was not violated nor did the survey remind them of adverse events. Data are presented in a way the identity of the respondents cannot be recognized.

\section{Instruments of research}

The instrument consisted of several parts (the role, demographic characteristics, understanding of the concept of complementary therapies, and attitudes about drinking tea for medical use). The central part, which was presented in this article, was a question checking the possible outcome if the patient brought their own tea mixture of medicinal plants to the hospital and wanted the nurse to prepare the tea. Respondents were to choose among the 11 previously prepared scenarios of possible responses of the nurse. Each respondent could decide for a maximum of three possible scenarios.

\section{Population sample}

Selection of the sample was aimed at including the various groups of people in the population: 
Residents of the local community, patients, nurses, and nursing students. Snowball sampling thus covered 506 persons from Southeast Slovenia. The response rate analysis was not possible due to the use of snowball sampling method. After elimination of incomplete/incorrect survey questionnaires, the final sample consisted of 427 persons, representing $84.4 \%$ of the primary sample. Primarily, the sample covered 25 (5.9\%) nurses, 82 (19.2\%) nursing students, 25 (5.9\%) patients in the time of hospitalization, and 295 (69.1\%) people without health education (persons for whom we could not claim they are not healthcare workers were not included in this group - their data were already eliminated at the beginning). Secondarily, "patients" and "residents" were grouped together into "general public," comprising 320 persons (74.9\%), and "nurses" and "nursing students" were grouped into the group "nursing care providers" which consisted of 107 persons $(25.1 \%)$.

\section{Data collection}

Trained for the purpose of surveying, 8 nursing students, members of the project group participated in performing the survey. The survey among residents and nursing students was mainly performed online, nurses completed the questionnaire on their own in person, and patients completed the questionnaire with the help of a student, member of the project group. By combining different methods, the problem of sampling, coverage, and representativeness was uniformed, as well as poor responsiveness of individual groups of the population in the online survey (31). The population groups differed due to certain characteristics; therefore, it was necessary to adjust the ways of completing the questionnaire (32).

\section{Statistical analysis}

Data were quantitatively analyzed using the program SPSS. 20. The basic statistics and the $\chi^{2}$-test of correlation were used, taking assumptions into account (33). The results are presented in the table, as well as in a descriptive way and interpreted in terms of feasibility, including the measures important for the research to be more efficient regarding the objectives (25), (34).

\section{RESULTS}

The results are presented separately, according to each possible scenario of expected reaction of nurses to the patient's request for preparing their tea. The exact question was: "If a patient brought a tea mixture of medicinal herbs with them to the hospital and asked (you) the nurse to prepare the tea for them, how would (you) the nurse respond?" The results show differences in the expected reaction of nurses between the groups of participants in the population: Nurses, nursing students, patients, and residents. At certain scenarios, the difference is statistically significant. Table 1 presents how many respondents (all together and as the individual groups) chose the given scenarios as one of the three most expected in percentage (\%) (Table 1).

The analysis of responses demonstrated differences regarding the expected reaction of nurses both within the groups, as well as between the groups of respondents. In general, speaking, the two most possible scenarios were the nurse would respond by collecting some information about the tea, consulting with the doctor, and after that, the tea would be prepared, and the tea would be prepared unhesitatingly. The most possible critical response of nurses would be to offer the tea which is daily available on the ward. As a very probable scenario was also chosen the one where the patient would not make the request because the tea would be provided by their visiting relatives. The biggest difference between the group "nursing care providers" and "general public" was in expectation of scenarios 1 or 10 . First, on merging the groups, the results statistically significant $\alpha<0.05\left(\chi^{2}=48.547(p<0.01)\right.$ show that nurses and nursing students as a united group "nursing care providers" are more convinced in the possibility of the first scenario as the "general public," the joint group of patients and residents of the local environment. Second, the results statistically significant $\alpha<0.05\left(\chi^{2}=8.968(p<0.01)\right.$ show that the group "general public" is more convinced in the scenario of patients not making the tea request to nurse because the tea would be provided by their visiting relatives.

Although we could not prove statistically significant differences within the merged groups, nevertheless, the following can be seen: 
TABLE 1. Selection of the expected reactions of nurses to the patient's request from the aspect of different groups of respondents

\begin{tabular}{|c|c|c|c|c|c|c|c|}
\hline \multirow[t]{2}{*}{ Group } & \multirow[t]{2}{*}{ Scenario } & \multicolumn{5}{|c|}{$\begin{array}{l}\text { The scenario was } \\
\text { chosen by } \mathrm{X} \% \text { of all: }\end{array}$} & \multirow[t]{2}{*}{ Gr. } \\
\hline & & AR & $\mathrm{N}$ & NS & $\mathrm{P}$ & $\mathrm{R}$ & \\
\hline $1^{\text {st }}$ & "The tea would be prepared unhesitatingly." & 20 & 60 & 40.2 & 24 & 12 & $\mathrm{~N}$ \\
\hline $2^{\text {nd }}$ & $\begin{array}{l}\text { "After collecting some information on the tea, and consulting with the doctor, the } \\
\text { tea would be prepared." }\end{array}$ & 35.5 & 24 & 70.7 & 362 & 27 & NS \\
\hline $3^{\text {rd }}$ & "Ignoring the request for the preparation of tea" & 15.5 & 0 & 1.2 & 4 & 22 & $\mathrm{R}$ \\
\hline $4^{\text {rd }}$ & "Apology for not preparing the tea due to the lack of time." & 16.6 & 8 & 2.4 & 4 & 22 & $\mathrm{R}$ \\
\hline $5^{\text {th }}$ & "Apology for not preparing the tea due to the lack of material possibilities." & 8.4 & 8 & 2.4 & 4 & 11 & $\mathrm{R}$ \\
\hline $6^{\text {th }}$ & $\begin{array}{l}\text { "The tea would not be prepared, instead the patient would be offered the tea } \\
\text { which is daily available on the ward." }\end{array}$ & 38.6 & 16 & 11 & 32 & 4 & $P$ \\
\hline $7^{\text {th }}$ & $\begin{array}{l}\text { "An excuse that they are unfamiliar with the tea for medical purposes would be } \\
\text { given by the nurse." }\end{array}$ & 7.7 & 0 & 3.7 & 4 & 10 & $\mathrm{R}$ \\
\hline $8^{\text {th }}$ & $\begin{array}{l}\text { "The patient would not make the request since the nurse does not have enough } \\
\text { knowledge." }\end{array}$ & 3.3 & 0 & 1.2 & 4 & 4 & $P, R$ \\
\hline $9^{\text {th }}$ & $\begin{array}{l}\text { "The patient would not make the request, because they may experience } \\
\text { disapproval by the nurse." }\end{array}$ & 8.3 & 8 & 1.2 & 4 & 25 & $P$ \\
\hline $10^{\text {th }}$ & $\begin{array}{l}\text { "The patient would not make the request, because the tea would be provided by } \\
\text { their visiting relatives." }\end{array}$ & 20.4 & 8 & 8.5 & 402 & 22 & $P$ \\
\hline $11^{\text {th }}$ & $\begin{array}{l}\text { "Even if the patient would not bring their own tea to the hospital, they would } \\
\text { expect the tea to be prepared." }\end{array}$ & 5.2 & 16 & 7.3 & 8 & 2 & $\mathrm{~N}$ \\
\hline
\end{tabular}

Legend: AR - X\% of all respondents; $N$ - X\% of all nurses; NS - X\% of all nursing students; $P$ - $X \%$ of all patients; $R-X \%$ of all residents; $G r$. - Group with the highest percentage of agreement

- Nursing students are more convinced in the scenario that the nurse would respond by collecting some information about the tea, consulting with the doctor, and after that prepare the tea. Nurses, however, are more convinced that the tea would be prepared unhesitatingly.

- Approximately a quarter of residents thinks that the nurse would ignore the patient's request or make an apology due to the lack of time, however, only a small amount of patients share the same opinion.

- Furthermore, almost a quarter of residents thinks that patients would not make the request, as they may experience disapproval by the nurse, but patients do not share the same view at all.

The least frequently chosen scenarios by all respondents were either the apology for not preparing the tea due to the lack of time or inappropriate material conditions. The respondents do not expect that the nurse would prepare the tea if the patients did not bring it with them.

\section{DISCUSSION}

The results of the research on determining what the expected reaction of nurses to the patient's request for complementary treatment with tea in hospitals (Table 1) would be by the nurses themselves, nursing students, patients, and residents of the local environment, have indicated the four fundamental issues:

- A great possibility of the scenario that the nurses would offer the tea which is daily available on the ward,

- A great possibility of the scenario that the patient would not ask the nurse for the tea, instead, and the tea would be provided by the visiting relatives,

- Negative opinion of the general public regarding the responsiveness of nurses to the patient's request for preparing their tea for the purpose of complementary medical treatment,

- Insufficient attention of all respondents regarding the knowledge of nurses.

The reaction of nurses that they would offer the tea which is daily available on the ward implies to 
considering the fact if nurses even hear and understand why the patient wishes the tea to be prepared. The findings of other studies suggest that responsiveness of nurses is better if they have already personally used alternative/complementary treatment. The more the treatment is perceived by the nurse as an effective, the larger should knowledge of the nurse regarding the treatment be $(35,36)$. Above all, the need for self-awareness of nurses is shown in understanding their own opinions, beliefs, and attitudes regarding the complementary/alternative treatment of patients and their role in the treatment, as well as obtaining new empirical data for taking actions more easily. Moreover, an issue of how cultural diversity influences the needs of patients to use complementary/alternative treatment could be important for further discussion. Therefore, it would be reasonable to modify the range of possible response scenarios by adding: "Before preparing the tea, the nurse would first check the patient's possible cultural customs and habits."

Another problem situation where the patient would rather ask their relatives for bringing them tea and not the nurse, raises the discussion on the possible causes of mistrust. Kennedy et al., (20) see the reasons for the potential mistrust in the fact that on disclosure of the patient's treatment with teas, the healthcare workers expressed their dissatisfaction, especially if the tea was not purchased in the pharmacy. Product purchased in the pharmacy, however, has a higher value for the treatment in the eyes of patients. It was also found that patients buy a product more often if its packaging reminds them of the pharmaceutical product (13). On the other hand, a serious situation, mainly due to the risk of contamination, misidentification, and interaction between treatments need to be considered as well (37). Qualitative research carried out in Canada showed that despite the high possibility of people using complementary treatments, the majority of healthcare workers admitted that they are not asking their patients about the use of medicinal plants for the purposes of medical treatment nor about their potential requests for that type of treatment (38).

The critical view of a quarter of the residents as respondents in our survey regarding the reaction of nurses indicates a negative public opinion about the responsiveness of nurses. It can be recognized in the chosen scenarios that the nurse would ignore the request, make an apology due to the lack of time or possibly express disapproval. The question arises, whether this kind of result can be considered as a generalized public opinion due to the presence of stereotypes or as a direct expectation associated with the view on alternative and complementary treatment due to the undefined normative bases. Tamlyn (38) indicates that only four channels through which we communicate with the world are at our disposal: What we do, what we look like, what we say, and how we say it. Nurses are thus building their image in public by more actively cooperating with the media and informing the public about the various activities of the profession. Using the thoughts of Kant, they "operate in a way that the maxim of their act can be considered as the principle of universal law" $(39,40)$.

Another problem was also recognized within the insufficient attention of respondents regarding the knowledge of nurses on responsiveness. 60\% of nurses would prepare the tea without any doubts, only $24 \%$ would consult the doctor, what may probably indicate that the nurses see the patient's request merely as an action: Preparation and serving the tea, but not as a form of treatment when the rules for administering medicine need to be considered. Accordingly, it would be reasonable to add the following scenario: "The nurse would prepare the tea for the patient, and report it to the doctor."

However, the results of the pilot study also indicate that the respondents were more focused on the category of direct action than on the circumstances that affect the action - knowledge. Regarding the expressed criticism about the knowledge of nurses, it is possible that the respondents gave more socially acceptable responses, or the other scenarios were actually more common to them. Nevertheless, the bright spot is undoubtedly the opinion of nursing students, who selected the most appropriate scenario: "After collecting some information about the tea, and consulting with the doctor, and the tea would be prepared." Unfortunately, this scenario was chosen by only a quarter of nurses and residents. It has been established by a number of studies that the nursing students reflect a positive attitude to alternative and complementary treatment and would like to gain more knowledge in this field. They believe 
that integration of this content in the curricula is important (41), but the problem occurs in the deficit of appropriate teachers $(42,43)$. It is, however, worth mentioning that since the times of Florence Nightingale, the nurses regard their work as something which includes and affects the mind, body, and spirit (44). "It is important to give the users of health services an opportunity to use the complementary treatments, based on evidence and knowledge offered by the nurses that are specialized in this area" (10). Despite the lack of organizational policies, resources and continuing education (45), nurses must be acquainted with the advantages and disadvantages of complementary/alternative treatments, as well as prepared to discuss and ask for help in resolving the ethical issues that surround them (46). Competencies for implementing integrative nursing care are based on "the intersection between knowledge, skills, attitudes, and values, as well as the mobilization of said components to transfer them to a context of the holistic treatment of patients" (47).

Above all, the question "do the anticipated scenarios adequately describe the range of possible responses of nurses to the patient's request for preparing their tea for the purpose of complementary medical treatment?" can be answered affirmatively. The feedback has been partially expected. Overall, for a more holistic approach, the study of on a larger scale should have more possible scenarios, providing even better insight into the responsiveness of nursing care providers to the request of the patient: 'Nurse, my tea, please!." A request to classify the scenarios from the most to the least ethical could be added. Furthermore, it would be reasonable to compare the expectations of groups of respondents by their age, previous experience, views on complementary/alternative treatment, personal experience of usage and participation in education regarding this field. It would undoubtedly be necessary to include doctors as the group of respondents since interprofessional cooperation is accepted as an important component in today's health care, and a condition for better results of treatment and safety of patients (48).

\section{Limitations}

It is in the nature of pilot studies that there are critical limitations in the role and interpretation, namely the results cannot be generalized. Limitations are derived from the sample; however, it has been noted that the samples in the size of $10-40$ respondents per group enable a sufficiently detailed estimate and can fulfill several objectives (49). The fact that various groups in the population answered differently is not to be regarded as a drawback since as a priority, it can cover several different population groups (32).

A significant restriction of pilot studies also orders to exclude the participants of the pilot study from the following studies of greater scope, since they react differently from those which, for example, do not know the possible scenarios in advance, irrespective of the changes in the instrument (50). All in all, the findings of a pilot study can be, regardless of the low informational value, of the utmost importance (27), since they include the measures and participant invitation for the research on a larger scale to be even more feasible, useful, and valuable $(25,34,51)$.

\section{CONCLUSION}

The study showed an alternative view of complementary treatment with tea in the hospital. The expected responsiveness of nurses to the patient's request for preparing their tea is pointing out a more-or-less critical view of different stakeholders on the nurse's work. It is necessary to increase the reputation of nurses in public for the relationship between nurses and patients - in terms of areas of alternative and complementary treatments - would be going in the direction of sharing information, consulting, dialogue, and partnership. The recognized issues are the so-called warnings for nurses to react, as well as they confirm the utility of the research effort. We provided the empirical evidence about the appropriateness and the feasibility of an innovative approach to examining this issue; however, it would be reasonable to further upgrade it. The usefulness of the study for health-care professionals and researchers in the international context is confirmed mainly due to the contextual scenarios and findings when trying to define an ethical response of nurses and other healthcare workers. In the name of the patient's right to choice and decision, equal opportunities, and holistic approach to a safe and high-quality medical treatment, the patients should be given an opportunity to an informed usage of alternative and complementary treatments, supported by evidence 
and knowledge, offered by the nurses who are specialized in the field.

\section{ACKNOWLEDGMENTS}

The project was cofinanced by the Slovene Human Resources Development and Scholarship Fund under the scheme called "creative path to practical knowledge" (Ur.l. št. 81/14), supported by the European Social Fund within the framework of the Operational Programme for Human Resources Development in the period 2007-2013. We would sincerely like to thank all the participants in the survey, the nursing students and their mentors for cooperating in the project Developing competencies for implementing integrative care of the patient: "Nurse, my tea, please!."

\section{REFERENCES}

1. CAMbrella. The Roadmap for European CAM research: CAMbrella European Policy Brief; 2012. Available from: http://www.cambrella.eu2012. [Last accessed on $2015 \mathrm{Dec} 10]$.

2. Tyreman S. Values in complementary and alternative medicine. Med Health Care Philos 2011;14:209-17. https://doi.org/10.1007/s11019-010-9297-5.

3. Stuttaford M, Al Makhamreh S, Coomans F, Harrington J, Himonga C, Hundt GL, et al. The right to traditional, complementary, and alternative health care. Glob Health Action 2014;7:24121.

https://doi.org/10.3402/gha.v7.24121.

4. Hollenberg D, Zakus D, Cook T, Xu XW. Re-positioning the role of traditional, complementary and alternative medicine as essential health knowledge in global health: Do they still have a role to play? World Health Popul 2008;10:62-75.

5. Ernst $E$, White $A$. The $B B C$ survey of complementary medicine use in the UK. Complement Ther Med 2000;8(1):32-6. https://doi.org/10.1016/S0965-2299(00)90833-1.

6. Ule MN. Spregledana Razmerja o Družbenih Vidikih Sodobne Medicine. Ljubljana: Arestej; 2003. p. 18.

7. Gale N. The sociology of traditional, complementary and alternative medicine. Sociol Compass 2014;8(6):805-22.

https://doi.org/10.1111/soc4.12182.

8. Webster M. Merriam-webster announces "socialism/capitalismus as 2012 word of the year. Available from: http://www.merriam-webster.com/pressrelease/2012-word-of-the-year. [Last accessed on 2015 Dec 10].

9. Adams J, Tovey P. Complementary and Alternative Medicine in Nursing and Midwfery. London, New York: Routledge Taylor \& Francis Group; 2008.

10. Kreitzer MJ, Koithan M. Integrative Nursing. London: Oxford; 2014.

11. Jolliffe L. Tea and Tourism: Tourists, Traditions, Transformations. Clevedon Hall: Francfurt Lodge, Channel View Publications; 2007.

12. Rivera JO, Loya AM, Ceballos R. Use of herbal medicines and implications for conventional drug therapy medical sciences. Altern Integ Med 2013;2:6. Available from: http://www.esciencecentral.org/journals/ use-of-herbal-medicines-and-implications-for-conventional-drug-therapy-medical-sciences-2327-5162.1000130.php?aid=15819. [Last accessed on 2016 Jun 24].
13. World Health Organization. WHO Guidelines on Good Agricultural and Collection Practices (GACP) for Medicinal Plants. Available from: http:/l www.apps.who.int/iris/bitstream/10665/42783/1/9241546271.pdf. [Last accessed on 2015 Dec 23].

14. Directive 2004/24/EC of the European Parliament and of Council of 31. Available from: http://www.ec.europa.eu/health/files/eudralex/vol-1/ dir_2004_24/dir_2004_24_en.pdf. [Last accessed on 2015 December 12; Last Published on 2004 Mar 31]

15. Tibult JC, Kaptchuk TJ. Herbal medicine research and global health: An ethical analysis. Bull World Health Organ 2014;86(8):577-656. Available from: http://www.who.int/bulletin/volumes/86/8/07-042820/en. [Last accessed on 2015 Dec 12].

16. International Council of Nurses. The ICN Code of Ethics for Nurses. Available from: http://www.icn.ch/images/stories/documents/about/icncode_english.pdf. [Last accessed on 2016 Jan 01; Last Published on 2012].

17. Frisch N. Standards for holistic nursing practice: A way to think about our care that includes complementary and alternative modalities. Online J Issues Nurs 2001;6(2):4. Available from: http://www.nursingworld. org/MainMenuCategories/ANAMarketplace/ANAPeriodicals/OJIN/ TableofContents/Volume62001/No2May01/HolisticNursingPractice.html. [Last accessed on 2016 Jun 23].

18. Silva MC, Ludwick R. Ethics: Ethical issues in complementary/alternative therapies. Online J Issues Nurs 2001;1. Available from: http://www.nursingworld.org/MainMenuCategories/ANAMarketplace/ANAPeriodicals/OJIN/ Columns/Ethics/Ethicallssues.html. [Last accessed on 2016 May 15].

19. Raal A, Volmer D, Sõukand R, Hratkeviš S, Kalle R. Complementary treatment of the common cold and flu with medicinal plants-results from two samples of pharmacy customers in Estonia. PLoS One 2013;8(3):e58642. Available from: http://www.eds.a.ebscohost.com.nukweb.nuk.uni-lj.si/ eds/pdfviewer/pdfviewer?vid=61\&sid=28d01d5c-50c1-4171-a71e-b54f598c501f\%40sessionmgr4007\&hid=4111. [Last accessed on 2016 Jun 05] https://doi.org/10.1371/journal.pone.0058642.

20. Kennedy J, Wang CC, Wu CH. Patent disclosure about herb and supplement use adults in the US. Evid Based Complement Alternat Med 2008;5(4):451-6.

https://doi.org/10.1093/ecam/nem045.

21. Loya AM, Gonzalez-Stuart A, Rivera JO. Prevalence of polypharmacy, polyherbacy, nutritional supplement use and potential product interactions among older adults living on the US-Mexico Border: A descriptive, questionnaire based study. Drugs Aging 2009;25:423-36. Available from: http:// www.eds.a.ebscohost.com.nukweb.nuk.uni-lj.si/eds/pdfviewer/pdfviewer?vid $=51 \&$ sid $=28 d 01 d 5 c-50 c 1-4171-a 71 e-b 54 f 598 c 501 f \% 40$ sessionmgr4007\&hid=4111. [Last accessed on 2016 Jun 16].

https://doi.org/10.2165/00002512-200926050-00006.

22. Tronto JC. Moral Boundaries: A Political Argument for An Ethics of Care. London: Routledge; 1993.

23. Haralambus M, Holborn M. Sociology: Themes and Perspectives. $1^{\text {st }}$ ed. Tran $4^{\text {th }}$ ed. Ljubljana: DZS; 2005, 1995.

24. Giddens A. Modernity and Self-identity: Self and Society in the Late Modern Age. Cambridge, U.K.: Polity press, Pasil Blackwell; 1991.

25. Arain M, Campbell MJ, Cooper CL, Lancaster GA. What is a pilot or feasibility study? A review of current practice and editorial policy. BMC Med Res Methodol 2010;10:67

https://doi.org/10.1186/1471-2288-10-67

26. Leon AC, Davis LL, Kraemer HC. The role and interpretation of pilot studies in clinical research. Psychiatr Res 2011;45:626-9.

https://doi.org/10.1016/j.jpsychires.2010.10.008.

27. van Teijlingen E, Hundley V. The importance of pilot studies. Nurs Stand 2002;16(40):33-6. Available from: http://www.fhs.mcmaster.ca/surgery/ divisions/postgrad/documents/Research7ReadingPilotStudies06Apr2011. pdf. [Last Accessed on 2016 Jul 03].

28. Mohorko A, Hlebec V. Effect of a first-time interviewer on cognitive interview 
quality. Qual Quant 2015;49(5):1897-918. Available from: http://www.link. springer.com.nukweb.nuk.uni-lj.si/article/10.1007\%2Fs11135-014-0081-0. [Last Accessed on 2016 Jun 01]

29. Polit DF, Beck CT, Hungler BP. Essentials of Nursing Research: Methods, Appraisal and Utilization. $5^{\text {th }}$ ed. Philadelphia: Lippincott Williams \& Wilkins; 2001.

30. Baker TL. Doing Social Research. $2^{\text {nd }}$ ed. New York: McGraw-Hill Inc; 1994.

31. Manfreda KL, Bosnjak M, Berzelak J, Haas I, Vehovar V. Web surveys versus other survey modes: A meta analysis comparing response rates. Indian J Med Res 2008;50:79-104. Available from: https://www.mrs.org.uk/ ijmr_article/article/87205. [Last Accessed on 2016 Jun 23].

32. De Leeuw ED, Hox JJ. Internet surveys as part of a mixed mode design. In: Das M, Ester P, Kaczmirek L, editors. Social and Behavioral Research and the Internet: Advances in Applied Methods and Research Strategies, (e-version). New York: Taylor \& Francis Group; 2011. p. 45-76.

33. Field A. Discovering Statistics using IBM SPSS statistics. London: SAGE Publications Inc; 2005.

34. Thabane L, Ma J, Chu R, Cheng J, Ismalia A, Rios LP, et al. Tutorial on pilot studies: The what, why and how. BMC Med Res Methodol 2010;10:1. Available from: http://www.bmcmedresmethodol.biomedcentral.com/articles/10.1186/1471-2288-10-1. [Last Accessed on 2016 Jun 22]. https://doi.org/10.1186/1471-2288-10-1.

35. Lindquist R, Tracy MF, Savik K. Personal use of complementary and alternative therapies by critical care nurses. Crit Care Nurs Clin North Am 2003:15:289-94

https://doi.org/10.1016/S0899-5885(02)00104-1.

36. Fearon J. Complementary therapies: Knowledge and attitudes of health professionals. Paediatr Nurs 2003;15(6):31-5. Available from: http://www.eds.a.ebscohost.com.nukweb.nuk.uni-lj.si/eds/pdfviewer/ pdfviewer?sid=28d01d5c-50c1-4171-a71e-b54f598c501f\%40sessionmgr4007\&vid=40\&hid=4111. [Last Accessed on 2016 May 02]

https://doi.org/10.7748/paed.15.6.31.s23.

37. Stupay S, Siversten L. Herbal and nutritional supplement use in the elderly. Nurs Pract 2000;25(9):56-8, 61-2, 64 https://doi.org/10.1097/00006205-200025090-00006.

38. Tamlyn D. The importance of image. Can Nurs 2005;101(4):26.

39. McDowell JE, Burman ME. Complementary and alternative medicine: A qualitative stady of beliefs of a small sample of Rocky Mountain area Nurses. Mesurg Nurs 2004;13(6):383-90. Available from: http://www. eds.a.ebscohost.com.nukweb.nuk.uni-lj.si/eds/pdfviewer/pdfviewer?vid $=29 \&$ sid $=28 \mathrm{~d} 01 \mathrm{~d} 5 \mathrm{c}-50 \mathrm{c} 1-4171-\mathrm{a} 71 \mathrm{e}-\mathrm{b} 54 \mathrm{f} 598 \mathrm{c} 501 \mathrm{f} \% 40$ session mgr4007\&hid=4111. [Last accesed on 2016 Jun 12].

40. Kunzmann P, Burkard FP, Wiedmann F. DTV Atlas Filozofije. Ljubljana: DZS; 1997

41. Kim SS, Erlen JA, Kim KB, Sok SR. Nursing students' and faculty members' knowledge of, experience with, and attitudes toward complementary and alternative therapies. Nurs Educ 2006:45(9):375-8. Available from: http://www.eds.a.ebscohost.com.nukweb.nuk.uni-lj.si/eds/pdfviewer/ pdfviewer?vid=17\&sid=28d01d5c-50c1-4171-a71e-b54f598c501f\%40sessionmgr4007\&hid=4111. [Last accessed on 2016 Jun 01].

42. Wyatt G, Post-White J. Future direction of complementary and alternative medicine (CAM) education and research. Semin Oncol Nurs 2005;21:215-24 Available from: http://www.sciencedirect.com.nukweb.nuk.uni-lj.si/science/ article/pii/S0749208105000422. [Last Accessed on 2016 Jun 12].

43. Booth-LaForce C, Scott CS, Heitkemper MH, Cormman BJ, Lan MC, Bond EF, et al. Complementary and alternative medicine (CAM) competencies of nursing students and faculty: Results of integrating CAM into the nursing curriculum. Prof Nurs 2010;26(5):293-300. Available from: http://www.sciencedirect.com.nukweb.nuk.uni-lj.si/science/article/pii/ S8755722310000372. [Last Accessed on 2016 Jul 03].

44. Ferrell B, Virani R, Jacobs HH, Malloy P, Kelly K. Arts and humanities in palliative nursing education. Pain Symptom Manage 2010;39(5):941-5. Available from: http://www.sciencedirect.com.nukweb.nuk.uni-lj.si/science/ article/pii/S0885392410002125. [Last Accessed on 2016 Jun 18].

45. Chu FY, Wallis M. Taiwanese nurses' attitudes towards and use of complementary and alternative medicine in nursing practice: A cross-sectional survey. Int J Nurs Stud 2007;44(8):1371-8.

https://doi.org/10.1016/j.jpurstu.2006.07.001.

46. Ernest $\mathrm{E}$, Cohen $\mathrm{MH}$, Stone J. Ethical problems arising in evidence based complementary and alternative medicine. Med Ethics 2004;30:1561-9. Available from: http://www.jme.bmj.com/content/30/2/156.full. [Last Accessed on 2016 Jun 18].

47. European Federation of Nurses Associations. EFN Competency Framework. EFN Guideline to Implement Article 31 into National Nurses' Education Programmes. Brussels, Belgium: European Federation of Nurses Associations; 2015.

48. Engel J, Prentice D. The ethics of inter professional collaboration. Nurs Ethics 2011;20(4):426-35. Available from: http://www. eds.a.ebscohost.com.nukweb.nuk.uni-lj.si/eds/pdfviewer/pdfviewer? sid $=28 d 01 d 5 c-50 c 1-4171-a 71 e-b 54 f 598 c 501 f \% 40$ session mgr4007\&vid=6\&hid=4111. [Last Accessed on 2016 May 25].

49. Hertzog MA. Considerations in determining sample size for pilot studies. Res Nurs Health 2008;31(2):180-91. Available from: http://www. eds.a.ebscohost.com.nukweb.nuk.uni-lj.si/eds/pdfviewer/pdfviewer?vid=3\&sid=28d01d5c-50c1-4171-a71e-b54f598c501f\%40sessionmgr4007\&hid=4111. [Last accessed on 2016 Apr 03]

50. Berger ML, Dreyer N, Anderson F, Towse A, Sedrakyan, A, Normand SL. Prospective observational studies to assess comparative effectiveness: The ISPOR good research practices task force report. Value Health 2012;15:217-30. Available from: http://www.sciencedirect.com.nukweb. nuk.uni-li.si/science/article/pii/S0885392410002125. [Last accessed on 2016 Jun 02] https://doi.org/10.1016/j.jval.2011.12.010.

51. Morin KH. Value of a pilot study. J Neural Eng 2013;52(10):547-8. Available from: http://www.healio.com/nursing/journals/jne/2013-10-52-10/\%7B4d3cd1c4-dd7a-4fea-8dd8-e96697dc6708\%7D/value-of-a-pilot-study. [Last accessed on 2016 May 23]. 